\title{
The location of eggs retained in the oviducts of mares
}

\author{
P. F. Flood*, Alida Jong † and K. J. Betteridge \\ Animal Pathology Division, Health of Animals Branch, Agriculture Canada, Animal Diseases \\ Research Institute (E), Box 11300, Station ' $H$ ', Ottawa, Ontario K2H 8P9, Canada
}

\begin{abstract}
Summary. The oviducts of 24 mares were examined to determine the site of retention of unfertilized eggs. The ampullary-isthmic junction regions of 42 of the 48 oviducts were serially sectioned and examined histologically. The remaining parts of the oviducts were flushed and the flushings searched microscopically. Of 45 eggs located, 40 were in the sectioned segments of 25 oviducts and only 5 were in the flushings. All but one of the sectioned segments contained prominent masses of material obstructing the lumen, but these were apparently not the direct cause of egg retention since eggs were found on both sides of them.
\end{abstract}

\section{Introduction}

The oviducts of the mare normally contain several ova in various stages of degeneration (van Niekerk \& Gerneke, 1966), and it seems that this is due to the selective retention of unfertilized eggs from successive cycles, only fertilized eggs regularly passing into the uterus. This view received strong support from the discovery of sperm-marked, degenerating eggs in the oviducts of mares 30 and 58 days after isolated matings (Betteridge \& Mitchell, 1974) but David (1975) has proposed that the degenerate tubal ova are derived from atypical ovulations.

There is evidence that the ova are retained in the middle third of the oviduct (Steffenhagen, Pineda \& Ginther, 1972; Oguri \& Tsutsumi, 1972) and that retention is associated with "globular masses" present in the same region (Onuma \& Ohnami, 1975) but no precise information is available on the position of the eggs or their relationship to the epithelium and the globular masses. Attempts to locate eggs in fixed, unsectioned oviducts cleared with benzyl benzoate, as described for rabbits (Longley \& Black, 1968), proved unsuccessful in mares (A. MacKenzie \& K. J. Betteridge, unpublished observations) and so the present study was designed to elucidate these points by histological techniques.

\section{Materials and Methods}

Reproductive tracts of 24 mares of unknown history were collected at a commercial slaughterhouse during May and June. Immediately after removal from the carcass, the ovaries and oviducts were placed in polythene bags on ice for the 90 -min journey to the laboratory. There, the ovaries were removed and sectioned by hand to examine follicles and corpora lutea. After removal of the mesosalpinx, the oviducts were laid flat and the ampullary-isthmic junction identified; this was recognizable as the point of most rapid narrowing of the tube. The portion of the oviduct extending about $1.5 \mathrm{~cm}$ on either side of the junction was excised, pinned flat on a card and fixed in Helly's fluid overnight. The remaining ampullary and isthmic segments were

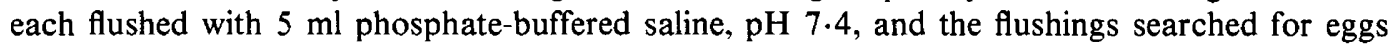

\footnotetext{
* Present address: Department of Anatomy, Western College of Veterinary Medicine, University of Saskatchewan, Saskatoon, Saskatchewan, S7N 0W0, Canada.

† Present address: Plaisance, Quebec, J0V 1S0, Canada.
} 
with a dissecting microscope. The fixed middle portion of the oviduct was processed for histology in the conventional manner and $15 \mu \mathrm{m}$ longitudinal sections were cut serially in the plane of the convolutions. Every fourth section was mounted and stained with haematoxylin and eosin. Where an egg was found, the adjacent sections were also prepared for microscopy. Of the 48 oviducts studied, 42 were examined histologically; the 6 that were not sectioned were those associated with the inactive ovary in the first 6 mares of the series.

\section{Results and Discussion}

One egg was recovered from the fluid flushed through the ampulla of each of 3 mares and in all 3 a functional corpus luteum was present in the ipsilateral ovary. Two of the eggs appeared to have been freshly ovulated but the third, which was associated with the largest and possibly the oldest corpus luteum, showed signs of degeneration. Only 2 eggs were recovered in flushings of the isthmus: one of these was a fresh egg found on the same side as a fresh corpus luteum and the other was a degenerate egg associated with an ovary containing no luteal tissue.

A total of 40 eggs were located in the ampullary-isthmic region of 25 of the 42 oviducts examined histologically. The numbers of eggs per oviduct were (with number of oviducts in parentheses): 1 (18), 2 (3), 3 (1), 4 (2) and 5 (1). Eggs were occasionally missed by this combination of methods, since none was found in 2 oviducts associated with recent ovulations.

Insofar as it was possible to judge from the fixed material, the eggs lay free in the lumen (Pl. 1, Fig. 1) and did not have any special relationship with the epithelium. The shape of the lumen was complex because of the extensive folding of the epithelium, but there was no evidence to suggest that the retained eggs had been diverted from the main channel and many clearly lay within it. However, the position of the eggs along the length of the oviduct was characteristic and they were always found just on the ovarian side of the point of most rapid narrowing and generally within the last loops of the ampulla (Text-fig. 1). The degree of degenerative change shown by each egg varied greatly (Pl. 1, Figs 1 and 2).

The "gelatinous" or "globular" masses, referred to by van Niekerk \& Gerneke (1966) and by Onuma \& Ohnami (1975), were a prominent feature of the oviducts examined in the present study and they were absent from only one of the ampullary-isthmic regions examined histologically. These masses could be seen through the walls of fresh oviducts held against the light. They were predominantly in the ampullary-isthmic region although they were occasionally recovered in flushings from the ampulla and isthmus. Histologically, the masses usually consisted of an eosinophilic material (Pl. 1, Fig. 3) but living cells were often present and occasionally numerous (Pl. 1, Fig. 4). On the basis of their histological examination of the oviducts of 5 mares, Onuma \& Ohnami (1975) also concluded that the masses were usually situated on the ovarian side of the ampullary-isthmic junction. They contended that the material was probably collagenous and was formed by desquamation from the oviductal epithelium; however, there was no histological evidence of cell loss from the epithelium in the present study. Further-

\section{PLATE 1}

Fig. 1. A recently ovulated egg characterized by relatively uniform cytoplasm and a thick, smooth and regular zona pellucida. $15 \mu \mathrm{m}, \mathrm{H} \& \mathrm{E} . \times 667$.

Fig. 2. An egg or possibly eggs in an advanced state of degeneration. The cytoplasm is sparse and the zona, although clearly recognizable, is thin and much folded. $15 \mu \mathrm{m}, \mathrm{H} \&$ E. $\times 695$.

Fig. 3. A typical mass. Although it does not entirely occlude the lumen, it probably occupies the major part of it. The texture of the plug is clearly distinguishable from other oviductal contents situated at either end of the plug and elsewhere (arrows). $15 \mu \mathrm{m}, \mathrm{H} \& \mathrm{E} . \times 42$.

Fig. 4. Material from a mass containing large numbers of cells. $15 \mu \mathrm{m}, \mathrm{H} \& \mathrm{E} \times 170$. 
PLATE 1
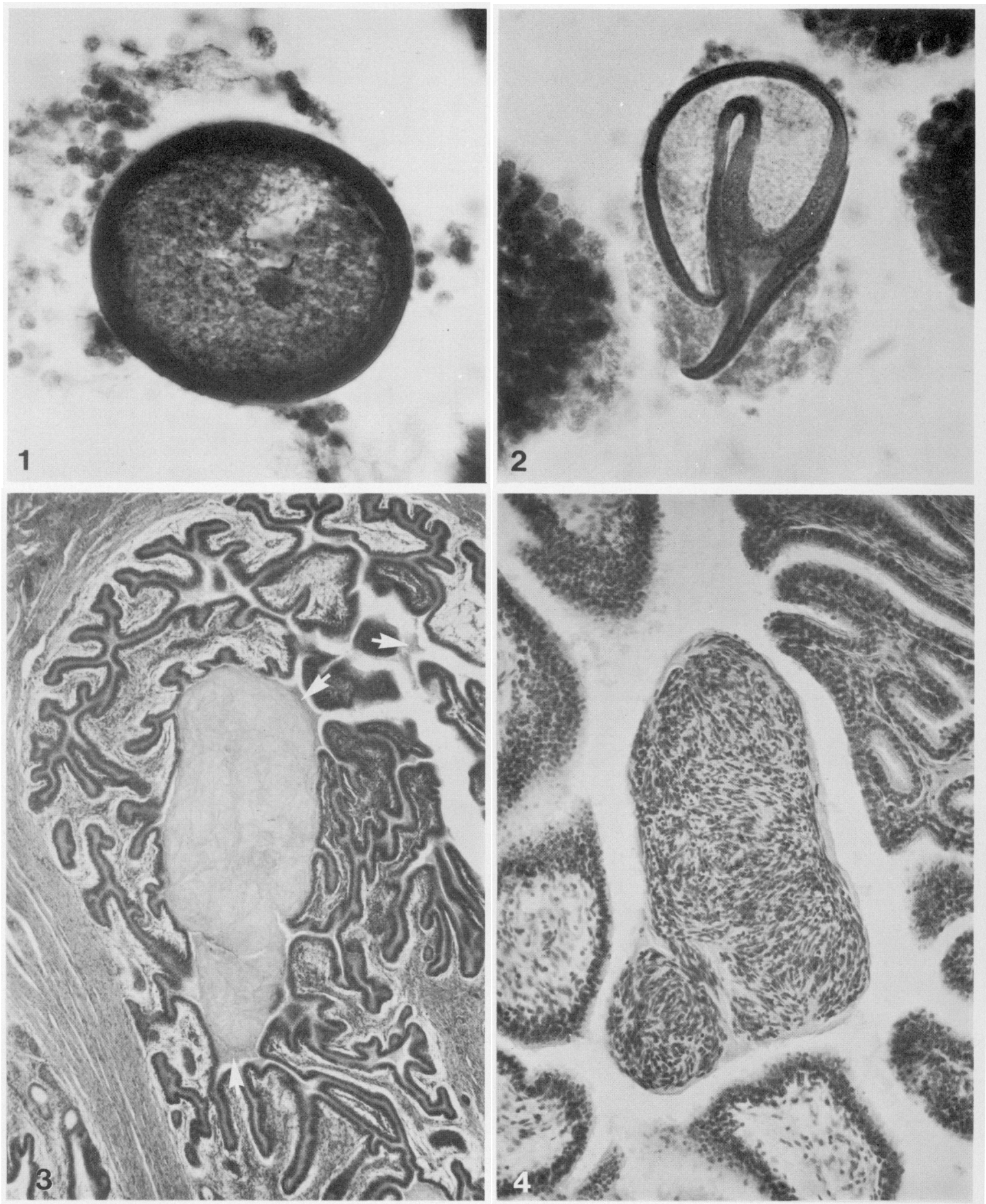

(Facing p. 292) 
more, their evidence that the masses contained collagen seems questionable and suggestions that the masses are of follicular origin (van Niekerk \& Gerneke, 1966; Oguri \& Tsutsumi, 1972) cannot be discounted.

Tsutsumi, Suzuki, Takeda \& Terami (1979) consider that the masses consist of collagen secreted by the tubal epithelium because of the collagen-like histological properties of the masses; areas of close apposition between the masses and the epithelium, and the presence of strands connecting the masses with the epithelium seen by scanning electron microscopy. Clearly these findings are open to a variety of interpretations and the unusual nature of the proposition requires more definitive evidence. The contents of the non-follicular cysts and clefts in the ovulation fossa (O'Shea, 1968) and debris from the peritoneal cavity might also contribute to their formation. The fact that the masses occur so frequently suggests that they are normal rather than pathological.

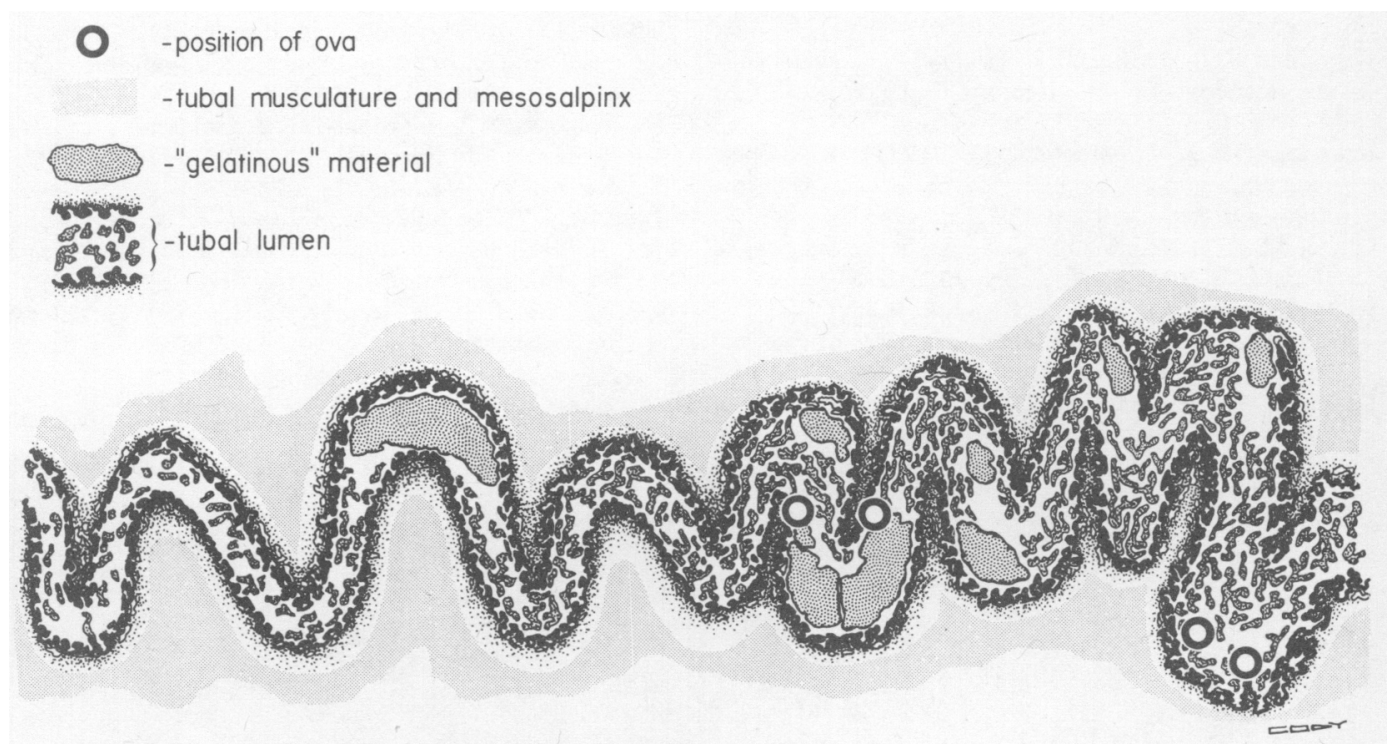

Text-fig. 1. A composite diagram from several sections of an oviduct containing 4 eggs. The ampulla is to the right and the isthmus to the left. The fine stippling represents related connective tissue. The gelatinous masses are shown in coarse stippling with a heavy outline. The positions, but not the sizes, of eggs are shown by the black circles.

In the present study the retained eggs did not show any consistent relationship with the masses. Even though the masses came close to completely occluding the lumen of the oviduct, eggs could be found on both the ovarian and uterine sides of the obstruction. The presence of masses and eggs may indicate a state of inertia in the ampullary-isthmic region that must be overcome by the embryo if it is to pass through.

It has previously been proposed that the horse embryo may influence its own transport by the production of a humoral agent (Betteridge, Flood \& Mitchell, 1976) and this study suggests that it is during transport through the ampullary-isthmic junction that this would be critical. Such an agent might influence the cilia or musculature of the oviduct or both of these. In the rabbit, at least, it is known that egg transport in the ampulla is influenced by muscular and ciliary activity, both of which are subject to pharmacological interference (Halbert, Tam \& Blandau, 1976). The observation that a developing embryo is capable of overtaking unfertilized eggs in the oviduct (Betteridge \& Mitchell, 1975; Onuma \& Ohnami, 1975) indicates that the hypothetical influence of the fertilized horse egg on the oviduct would have to be of a local rather than a generalized nature. 
This work was carried out during tenure of a post-doctorate fellowship of the National Research Council of Canada by one of us (P.F.F.). We are also grateful to the Pathology section of this Institute for provision of histological facilities and advice, and to Gary Cody of the Department of Anatomy, Western College of Veterinary Medicine, for the drawing.

\section{References}

Betteridge, K.J., Flood, P.F. \& Mitchell, D. (1976) Possible role of the embryo in the control of oviductal transport in mares. In Ovum Transport and Fertility Regulation, pp. 381-389. Eds M. J. K. Harper, C. J. Pauerstein, C. E. Adams, E. M. Coutinho, H. B. Croxatto \& D. M. Paton. Scriptor, Copenhagen.

Betteridge, K.J. \& Mitchell, D. (1974) Direct evidence of the retention of unfertilized ova in the oviduct of the mare. J. Reprod. Fert. 39, 145-148.

Betteridge, K.J. \& Mitchell, D. (1975) A surgical technique applied to the study of tubal eggs in the mare. J. Reprod. Fert., Suppl. 23, 519-524.

David, J.S.E. (1975) A survey of eggs in the oviducts of mares. J. Reprod. Fert., Suppl. 23, 513-517.

Halbert, S.A., Tam, P.Y. \& Blandau, R.J. (1976) Egg transport in the rabbit oviduct. The roles of cilia and muscle. Science, N.Y. 191, 1052-1053.

Longley, W.J. \& Black, D.L. (1968) Comparisons of methods for locating ova in the oviduct of the rabbit. J. Reprod. Fert. 16, 68-72.
Oguri, N. \& Tsutsumi, Y. (1972) Studies on lodging of the equine unfertilized ova in fallopian tubes. Res. Bull. Livestock Farm, Hokkaido Univ. 6, 32-43. (In Japanese.)

Onuma, H. \& Ohnami, Y. (1975) Retention of tubal eggs in mares. J. Reprod. Fert., Suppl. 23, 507-511.

O'Shea, J.D. (1968) A histological study of non-follicular cysts in the ovulation fossa region of the equine ovary. J. Morph. 124, 313-320.

Steffenhagen, S.P., Pineda, M.H. \& Ginther, O.J. (1972) Retention of unfertilized ova in uterine tubes of mares. Am. J. vet. Res. 33, 2391-2398.

Tsutsumi, Y., Suzuki, H., Takeda, T. \& Terami, Y. (1979) Evidence of the origin of gelatinous masses in the oviducts of mares. J. Reprod. Fert. 57, 287-290.

van Niekerk, C.H. \& Gerneke, W.H. (1966) Persistence and parthenogenetic cleavage of tubal ova in the mare. Onderstepoort. J. vet. Res. 33, 195-232.

Received 7 November 1978 